\title{
Websites and Apps used by Women to access Infant Feeding Information
}

\author{
L. Mullaney ${ }^{1}$, A. O’Higgins ${ }^{2}$, S. Cawley ${ }^{1}$, R. Kennedy ${ }^{1}$, D. McCartney ${ }^{1}$ and M.J. Turner ${ }^{2}$ \\ ${ }^{1}$ School of Biological Sciences, Dublin Institute of Technology, Dublin 8, Republic of Ireland and ${ }^{2} U C D$ Centre for \\ Human Reproduction, Coombe Women and Infants University Hospital, Dublin 8, Republic of Ireland
}

A recent study found that women using maternity services in Ireland in 2012-2013 reported a high usage of digital media to obtain pregnancy information. ${ }^{1}$ A UK study suggests that first-time mothers have a good understanding of the weaning guidelines but seek weaning information from multiple sources, much of which is conflicting. There is thus a concern about mis-information in this area. ${ }^{2}$ The aim of this study was to assess website and application use by women to access infant feeding information.

Women who had attended the Coombe hospital for antenatal care were asked at approximately nine months postpartum, in an unsupervised computer based questionnaire, dichotomous questions about whether they had used websites or apps to get information on infant feeding. If women had used websites or apps, they were asked to name the websites and apps they had used. These websites and apps were then categorised into public, commercial, or professional groupings.

The mean age of the sample $(n=295)$ was $32.6 \pm 4.8$ years, mean weight was $69.6 \pm 14.7 \mathrm{~kg}$, with $15.9 \%$ obese and $42.7 \%$ nulliparous. Of the 292 women who responded to the question, 156 women $(53.4 \%)$ reported not using websites to access information on infant feeding. The remaining 136 women $(46.6 \%)$ reported the websites they used and 108 of these women $(86 \%)$ reported using public websites (Table 1). Of the original 295 women, 27 (9.2\%) reported using apps to get information on infant feeding. All of the apps used for this purpose were public apps.

Table 1 Which Websites Do You Mainly Use? $(\mathrm{n}=136)$

\begin{tabular}{|c|c|c|c|}
\hline & & Number & Percentage \\
\hline \multirow[t]{2}{*}{ Professional } & HSE website & 4 & $2 \cdot 9$ \\
\hline & Safefood & 2 & 1.5 \\
\hline \multirow[t]{4}{*}{ Commercial } & First 1000 days & 11 & $8 \cdot 1$ \\
\hline & Aptamil Website & 4 & $2 \cdot 9$ \\
\hline & Miliupa & 5 & $3 \cdot 7$ \\
\hline & SMA & 2 & $1 \cdot 5$ \\
\hline \multirow[t]{10}{*}{ Public } & Parenting & 1 & $7 \cdot 4$ \\
\hline & Anabel Karmel & 25 & $18 \cdot 4$ \\
\hline & Baby Centre & 24 & $17 \cdot 6$ \\
\hline & Baby Led Weaning & 10 & $7 \cdot 4$ \\
\hline & EU Mom & 18 & $13 \cdot 2$ \\
\hline & Google & 3 & $2 \cdot 2$ \\
\hline & Rollercoaster & 9 & $6 \cdot 6$ \\
\hline & Mummy Pages & 4 & $2 \cdot 9$ \\
\hline & Kelleymom & 2 & $1 \cdot 5$ \\
\hline & Other & 12 & $8 \cdot 8$ \\
\hline
\end{tabular}

The use of internet forums should be recognized and leveraged in devising weaning communication strategies. The high use of public websites which are not regulated has potentially serious consequences as there is a risk of misinformation or conflicting information.

1. O’Higgins A, Murphy OC, Egan A et al. (2014) Ir Med J 107, 313-5

2. Moore AP, Milligan P, Rivas C et al. (2012) Pub Health Nutr 15, 1661-1669 